\title{
TÍTULO DO TRABALHO: POLUIÇÃO DO RIO SÃO PATRÍCIO POR USINA SUCROALCOOLEIRA NO TERRITÓRIO DE ITAPACI-GO.
}

\author{
AMANDA BLANCO SALINAS GUEDES VIEIRA
}

AMANDABLANCO_@OUTLOOK.COM

PONTIFÍCIA UNIVERSIDADE CATÓLICA DE GOIÁS

FERNANDA CAROLINE ROMANIELO ALVES

FERNANDARCAROLINE@HOTMAIL.COM

PONTIFÍCIA UNIVERSIDADE CATÓLICA DE GOIÁS 
1. RESUMO

Itapaci é um município goiano localizado no Vale de São Patrício, mesorregião central de Goiás e microrregião de Ceres. Começou a se desenvolver a partir da década de 1940 com a política da Marcha para o Oeste, criada pelo governo federal. Chamada de "A Princesinha do Vale", Itapaci também é lembrada pelas instalações de uma Usina Sucroalcooleira. A Usina possui capacidade produtiva de 2,5 milhões de toneladas de cana por safra, 90 mil toneladas de açúcar e $154 \mathrm{~m}^{3}$ de etanol. Em lugar privilegiado situa-se próximo a ferrovia Norte-Sul e tem acesso para as rodovias que levam a mercados de Brasília, norte de Goiás, Tocantins e Bahia. A Produção Mais Limpa, forma de diminuição dos passivos ambientais, é um processo já observado nas Usinas Sucroalcooleiras, desta forma tentam minimizar os impactos ambientais causados pelo processo produtivo de seus subprodutos.

Palavras-chave: Vale de São Patrício, Impactos Ambientais, Usinas Sucroalcooleiras.

\section{INTRODUÇÃO/OBJETIVO}

O Rio São Patrício é um rio brasileiro do Estado de Goiás pertencente a Bacia Hidrográfica Tocantins-Araguaia. Esse rio faz a divisa natural entre os municípios de Rubiataba e Nova América, e Rubiataba e Itapaci.

Itapaci é um município goiano localizado no Vale de São Patrício, mesorregião central de Goiás e microrregião de Ceres. Começou a se desenvolver a partir da década de 1940 com a política da Marcha para o Oeste, criada pelo governo federal. Chamada de "A Princesinha do Vale", Itapaci também é lembrada pelas instalações de uma Usina Sucroalcooleira.

A Usina possui capacidade produtiva de 2,5 milhões de toneladas de cana por safra, 90 mil toneladas de açúcar e $154 \mathrm{~m}^{3}$ de etanol. Em lugar privilegiado situa-se próximo a ferrovia Norte-Sul e tem acesso para as rodovias que levam a mercados de Brasília, norte de Goiás, Tocantins e Bahia. 


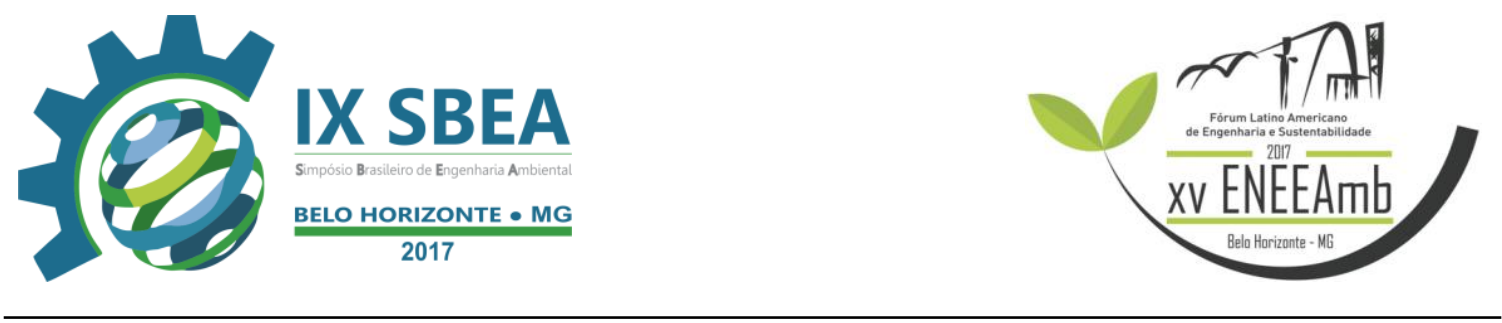

[...] A implantação e o desenvolvimento de sistema sucroalcooleiro envolve um conjunto de usinas e de áreas de plantio ao seu redor, em manchas continuas e normalmente implica em vários impactos: os impactos no uso de recursos matérias (principalmente energia e matérias); os impactos no meio ambiente(qualidade do ar; clima global; suprimento de água; ocupação do solo e biodiversidade; preservação dos solos; uso de defensivos e fertilizantes); a sustentabilidade da base de produção agrícola; com a resistência a pragas e doenças; impactos nas ações comercias, tratando de competitividade e subsídios; e finalmente os impactos sócios econômicos, com grande ênfase na geração de emprego e renda.

De acordo com GONÇALVES apud SILVA, BARBALHO e ANDRADE (2013): Outros problemas ambientais envolvendo pincipalmente os recursos hídricos, são recorrentes, como o consumo elevado de água para a irrigação, para a lavagem de cana nas usinas, risco de contaminação dos corpos hídricos pelo despejo de água de lavagem sem tratamento, o risco de contaminação por agrotóxicos e pela vinhaça, que também é usada como fertilizante, e o risco de contaminação de lençóis subterrâneos.

Sabe-se que o agronegócio de cana-de-açúcar retoma-se ao tempo da colonização do país. Segundo Araújo (2011), esse setor possui grande importância econômica, social e ambiental, sendo grande gerador de ocupação no meio rural, com geração de divisas e produção de energia renovável e limpa.

Apesar de toda a modernização tecnológica do processo produtivo de açúcar e etanol, algumas técnicas tradicionais como a queima da palha da cana para a facilitação da colheita manual ou mecânica ainda se mantem. Analisando esta única informação, pode-se observar que impactos sociais e ambientais são pulsantes neste tipo de cultivo.

O presente artigo tem por objetivo analisar de forma generalizada os impactos ambientais e sociais causados por uma usina sucroalcooleira, tomando por exemplo a usina localizada no município Itapaci - Go. 


\section{METODOLOGIA}

Tabela 1- Índice de qualidade da água

\begin{tabular}{|l|l|}
\hline PARÂMETROS & \\
\hline OD(mg/L) & 7,60 \\
\hline Coliformes Termotolerante (NMP/100Ml) & 300,00 \\
\hline Ph & 7,70 \\
\hline DBO 5,20 (mg O2/L) & - \\
\hline Temperatura da água $\left({ }^{\circ} \mathrm{C}\right)$ & 23,40 \\
\hline Turbidez/NTU & 18,60 \\
\hline Sólidos Dissolvidos Totais (TDS mg/L) & 28,30 \\
\hline
\end{tabular}

Fonte : Relatório SEMARH Qualidade das Águas 2013

A metodologia aplicada fundamentou-se em uma visita feita por uma das autoras do artigo ao Rio São Patrício; pesquisas bibliográficas referentes ao tema em discussão, abordando as ações e levantando informações que possibilitem uma gestão ambiental mais eficiente para o processo produtivo da usina; além de um questionário (em apêndice) aplicado a um funcionário anônimo da referida empresa.

Os dados foram obtidos pela participação direta dos autores do artigo nas fases de elaboração através da internet, por meio de artigos, por fotos e entrevista onde foram identificadas as definições de contexto e conceito sobre usinas sucroalcooleiras e seus devidos processos.

Apêndice

\section{Questionário:}

1- Existe alguém responsável pela parte ambiental da empresa? 


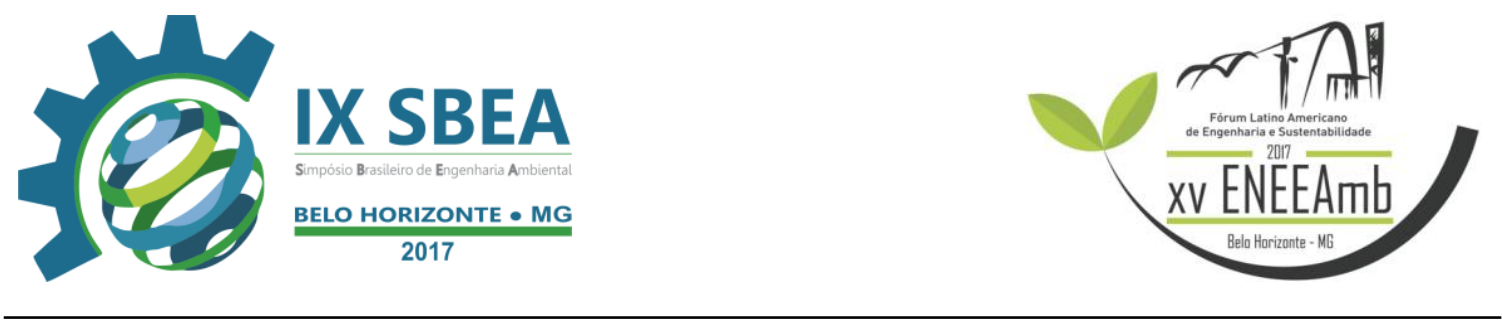

2- Há um tratamento para os resíduos despejados neste rio?

3- A empresa utiliza os chamados "bóias frias" para colheita da cana?

Se sim, a empresa está dentro das normativas trabalhistas quanto a estes trabalhos?

4- A empresa possui algum projeto sócio-ambiental que envolva a comunidade local?

5- A vinhaça é utilizada como fertilizante?

6- Existe a queimada palha de cana para facilitar a colheita?

7- Como são tratados esses resíduos?

\section{Resposta:}

1- Sim, uma Engenheira Ambiental.

2- Sim, integralmente como a legislação exige.

3- Sim. Sim, também.

4- Sim, são disponibilizados mudas de plantas para plantação na cidade, tanto em locais que são feitas as queimas, quanto na parte urbana.
5- Sim.
6- Sim.
7- São tratados conforme a legislação.

\section{RESULTADOS E DISCUSSÃO}

Como não foi autorizado uma visita a usina (Figura 1), as informações deste artigo são dados de pesquisas de outrem e respostas de um funcionário não específico da área socioambiental, assim os resultados são imprecisos, porém as discussões são sugestões para uma melhor eficiência nas questões socioambientais da empresa. 
Dentro de uma indústria sucroalcooleira o resíduo líquido é gerado tanto na produção, quanto em áreas administrativas (banheiros, refeitórios, entre outros).

A vinhaça, subproduto com potencial poluidor, que apresenta elevado teor de matéria orgânica (DBO de 20 mil a $35 \mathrm{mil} \mathrm{MG/L}$ ), com pH variando de 3,5 a 5,0 . Este alto índice de DBO pode contaminar a água subterrânea e manancial superficiais, devido à percolação ou arraste de altas concentrações de amônia, magnésio, alumínio, ferro, manganês, cloreto e matéria orgânica ou alterar as características do solo.

O tratamento de efluentes da usina sucroalcooleira pode ser dividido em duas etapas principais:

-Tratamento preliminar onde o efluente é submetido a uma sequência de processos, o gradeamento, desarenador, calha parshall e pelo tanque de equalização e assim se torna adequado para o tratamento biológico.

-Tratamento biológico constituído pela associação do tratamento anaeróbio e posterior tratamento aeróbio, através de biodigestores e tratamento por lodo ativado, respectivamente.

Após o tratamento dos efluentes da usina, o mesmo é lançado no Rio São Patrício. (Figuras 2 e 3)

Fonte: Funcionário Anônimo, 2016.

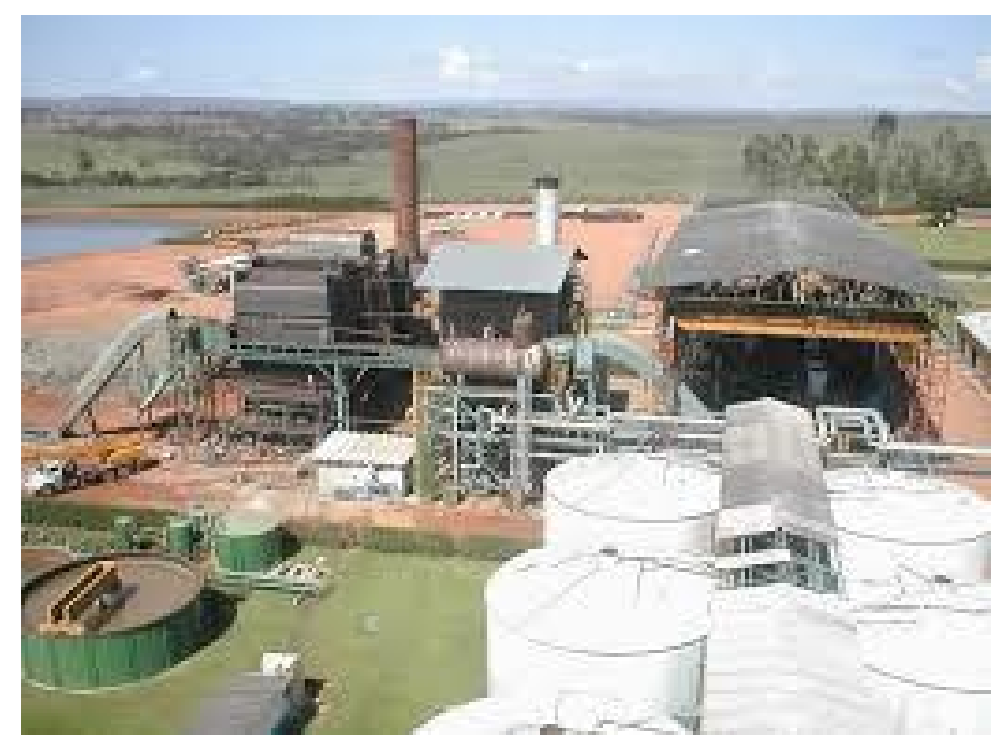




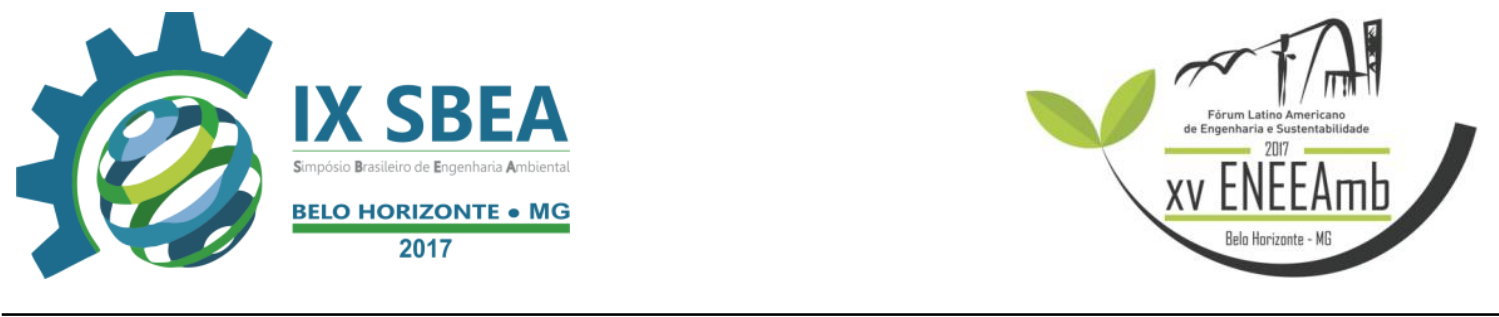

Figura 1: Usina Vale Verde, Itapaci - GO

Fonte: Fernanda Romanielo, 2016.

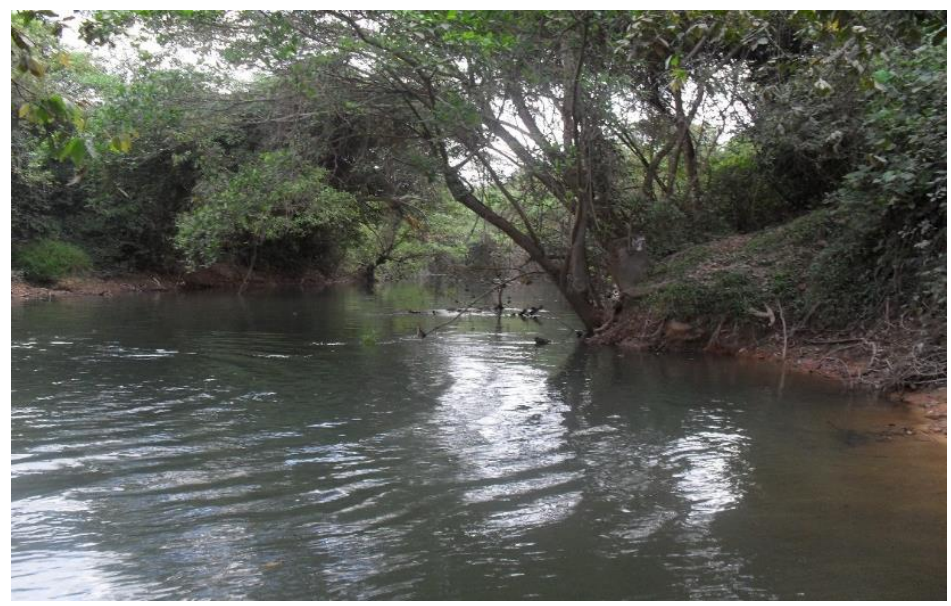

Figura 2: Rio São Patrício, Itapaci - GO.

Fonte: Fernanda Romanielo, 2016.

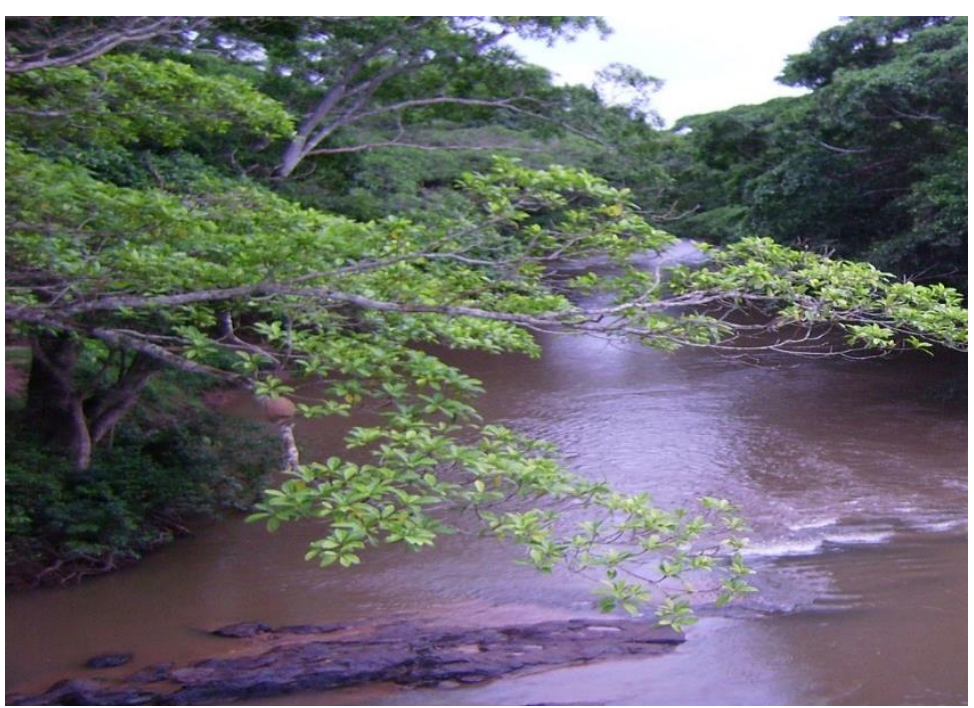

Figura 3: Rio São Patrício, Itapaci - GO. 


\section{CONCLUSÕES/RECOMENDAÇÕES}

Em virtude do exposto, conclui-se que uma Indústria Sucroalcooleira contradiz todo o contexto de sustentabilidade pregado sobre o uso do seu subproduto, no caso o etanol, embora usem como pressuposto para sua instalação o aumento da oferta de emprego e o desenvolvimento da região.

As Usinas reconhecem todos os impactos gerados na produção do álcool e açúcar, destacando-se a contaminação das águas e solos, quando os resíduos são descartados sem nenhum tipo de tratamento, de forma errônea, no meio ambiente. Ressaltando que todos os rejeitos gerados por uma indústria devem estar de acordo com a legislação vigente, assim como as normas trabalhistas e programas sociais que envolvam a comunidade local.

Recomenda-se um estudo mais aprimorado sobre formas de melhoria para os passivos ambientais e impactos sociais.

\section{REFERÊNCIAS BIBLIOGRÁFICAS}

ALVARENGA, Rafael Pazeto; QUEIROZ, T. R. Produção mais limpa e aspectos ambientais na indústria sucroalcooleira. In: International Workshop Advances in Cleaner Production. São Paulo, mai. 2009. Disponível em: $<$ http://www. advancesincleanerproduction.net/second/files/sessoes/4a/3/T.\%20R.\%20Queiroz $>$. Acesso em 03 de nov. 2016.

ARAÚJO, Valterlan Teixeira. Impactos socioeconômicos, na família dos pequenos proprietários rurais: consolidação da empresa agrícola da cana-deaçúcar em Itapaci-GO. Cadernos CERU, v. 22, n. 1, p. 95-112, 2011.

BRASIL; Resolução CONAMA nº 01, de 23 de maio de 1986. Dispõe sobre critérios básicos e diretrizes gerais para avaliação de impacto ambiental. Diário Oficial da União, Brasília, DF, fev. 1986. Disponível em: $<$ http://www.mma.gov.br/port/conama/legiabre.cfm?codlegi=23>. Acesso em: 06 de nov. 2016.

CORAZZA, Rosana Icassatti et al. Impactos Ambientais Da Vinhaça: Controvérsias Científicas E Lock-In Na Fertirrigação?. In: 44th Congress, July 


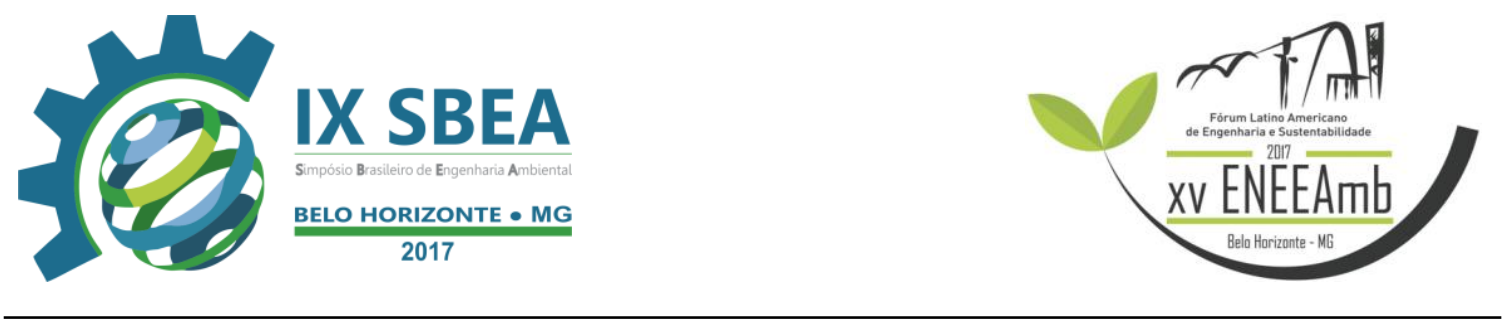

23-27, 2006, Fortaleza, Ceará, Brazil. Sociedade Brasileira de Economia, Administracao e Sociologia Rural (SOBER), 2006.

DUTRA, Sandro et al. A EXPANSÃO SUCROALCOOLEIRA E A DEVASTAÇÃO AMBIENTAL NAS MATAS DE SÃO PATRICIO, MICRORREGIÃO DE CERES, GOIÁS. História, histórias, v. 1, n. 1, p. 230-247, 2013.

Disponível

em:

http://www.periodicos.unb.br/index.php/hh/article/view/10368> . Acesso em: 03 de nov. 2016.

NOGUEIRA, MAFDES; GARCIA, M. DA S. Gestão dos resíduos do setor industrial sucroenergético: estudo de caso de uma usina no município de Rio Brilhante, Mato Grosso do Sul. Revista Eletronica em Gestão, Educação e Tecnologia Ambiental-REGET, v. 17, n. 17, p. 3275-3283, 2013.

SILVEIRA, Gustavo Echenique. Sistemas de tratamento de efluentes industriais. 2010.

TRINDADE, Silas Pereira; CHAVES, Manoel Rodrigues. Sustentabilidade do setor sucroalcooleiro em Goiás: relação da produção agrícola e impactos ambientais. IV Singa, Niterói, 2009. 